\title{
PSICANÁLISE, SEDIMENTAÇÃO E DERIVA: REFLEXÕES SOBRE OS MOVIMENTOS DE UMA HISTÓRIA REAL.
}

\author{
Osmar Luvison Pinto \\ Psicanalista do Instituto de Psicanalise da Sociedade Brasileira de Psicanálise de São Paulo.
}

RESUMO: O artigo trata de algumas características internas do ser humano, visto como objeto de estudo de psicanalistas e de profissionais ligados às Ciências Humanas. $O$ interior do homem é abordado do ponto de vista psicanalítico, como estrutura constituida de movimentos incessantes. Isto requer do pesquisador uma flexibilidade metodológica; uma postura diante do fenômeno que possa incluir tanto as instabilidades do homem investigado como do homem que investiga. Freud ao desenvolver o método psicanalítico procurou levar em consideração a relaçāo entre realidades internas do paciente e do analista. $O$ texto relata parte dessa história, sugerindo o método psicanalítico como referencial útil ao pesquisador de outras áreas.

ABSTRACT: This article studies about some inner characteristics of the human being, regarded as object of study of psychoanalysts and professionals in the field of Human Sciences. Man's inner side from a psychoanalytical viewpoint is a structure constituted of continuous movements. The researcher is required to have a methodological flexibility - an attitude before the phenomenum that can include the instabilities of both the researcher and the patient. When developing the psychoanalytical method, Freud tried to take into account the relations between the patient's and the analyst's inner realities. This paper reports part of this story, suggesting that the psychoanalytical method is a useful reference for researchers in other fields.

PALAVRAS-CHAVE: Método, realidade, movimento, objeto, virtualidade.

KEYWORDS: method, reality, movement, object, virtuality

"Uma voz racional calou-se. Sobre sua tumba,
a família do Impulso pranteia um ente querido.
Eros está triste, o construtor de cidades;
chora a anárquica Afrodite."
Trecho do poema "Em memória de Sigmund Freud" .

(AUDEN, 1986, p. 101)

\section{Os objetos e suas realidades fugazes}

Cada vez mais comuns são as tentativas de troca entre as áreas do conhecimento que têm no homem e nas produçōes humanas seu principal objeto de estudo. Temos observado uma espécie de desenvol- 
vimento das idéias, sustentado na abertura de fronteiras interdisciplinares; tal abertura promove mo. vimentos na relação do investigador para com seu objeto, configurando um senso ético bastante relevante para o tratamento das questões do homem: a ética que reserva um lugar para a incompletude. Não se trata, evidentemente, do abandono da "formação específica" de cada pesquisador, perfil essencial que oferece um cixo inteligível e compartilhável às hipoteses de trabalho; trata-se, sobretudo, da diffcil assunção de que somos menores que os fenômenos que nos propomos abordar. Daí a necessidade do que poderíamos chamar de alteridade intelectual, representada pela multidisciplinariedade, trabalhando como clemento regulador de nosso natural ímpeto de domínio sobre um objeto, $\mathrm{cm}$ última análise, indefeso.

A complexidade inerente à pesquisa humanista demanda um equilíbrio dinâmico dentro do vínculo pesquisador-objeto; este, se levado a bom termo, resulta em posturas investigativas arejadas, sempre vetorizadas no sentido da flexibilização dos métodos investigativos, desta forma capacitados a identificar sutilezas que o excessivo apego metodológico pode desconsiderar. Em outras palavras, o sentido do termo flexibilização é o de permitir accsso a todo vestígio de vida encontrado em cada manifestação daquele homem que se apresenta ao filósofo, ao psicanalista, ao historiador, ao sociólogo, ao médico, ao artista etc. Para tanto, exigese de cada especialista, o cuidado de não csgotar o fenômeno (aparentemente um paradoxo científico) ao qual tem acesso, evitando assim o encarceramento voraz do sujeito individual ou coletivo, do passado ou do presente, que, por sua própria infinitude estrutural, acabou gerando tantas formas possíveis de abordagem.

A experiência psicanalítica indica que o sucesso em seus desafios (terapêuticos ou teóricos) depende, em grande parte, do tipo de disposiçāo psíquica que se faz presente no interior do analista, diante das características dinâmicas que se expressam tanto no discurso do paciente como na pulsação da produção conceitual. Como analistas, somos instados a transitar por territórios movediços, idealmente, sem invadí-los e sem nos deixarmos capturar. Na verdade, isto que romanticamente se parece com uma "odisséia" do cotidiano, pode ser representado por uma habilidade mental instalada entre a sedimentação e a deriva; dois movimentos naturais que têm lugar no interior do investigador, transitando pelo vínculo com o fenômeno que está diante dele. Da perspectiva de quem investiga, existe seu próprio território móvel a ser levado em conta; um "objeto paralelo" dentro do qual se instalam disposições subjetivas. Diantc deste quadro, dois caminhos possíveis: ou a atitude negadora que sugere a exclusão da subjetividade do analista como se ela fosse um "ruído", ou o esforço ético que amplia o conceito de realidade (via de regra o lugar da objetividade), concedendo à subjetividade do investigador, um espaço legítimo dentro deste largo espectro fenomenológico. Seria esta uma questão que interessa somente aos psicanalistas? Talvez nāo. O mais provável é que na Psicanálise csta questão csteja presente de maneira mais contundente. Desde os primeiros tempos, a atividade clínica vai criar a figura do investigador da alma (ou da intimidade), de quem não se deve guardar segredos e por quem se experimenta sentimentos dos mais variados matizes. É natural, portanto, que a Psicanálise se ocupe do que ocorre com o analista; ele é o alvo da situação transferencial que se engendra no setting analítico. Espera-se, desde os primórdios da Psicanálise, que ele se dedique ao manejo da transferência, fonte de abastecimento da conduta interpretativa. Todavia, a construção da interpretação parte, muitas vezes, do material que 0 analista reçolhe em si mesmo, como uma "bússola" onde o norte está representado pelos percursos psíquicos trilhados pelo profissional. 
Voltando à pergunta formulada anteriormente, que obviamente ficará em aberto, podemos dizer que a Psicanálise coloca de modo radical, uma questão que também habita o universo do historiador: a realidade, reino objetivante, onde se dão fatos, onde estão os documentos comprobatórios da História, não exclui um outro fato, que aponta para a singularidade do historiador como participante ativo da construção do documento histórico; singularidade movida por sentimentos, sensaçōes e fantasias que, em última análise, prestam-se também como norteadores da pesquisa histórica. Ao que tudo indica, o movimento interno do historiador, é um dos instrumentos que lhe dá acesso à dinâmica daquele autor de outros tempos, que colocou no papel, na tela, ou na pedra, seus próprios movimentos. A tarefa decorrente de tais afirmações, tanto para o psicanalista como para o historiador é, incluir no campo metodológico, a busca de uma justa compatibilidade entre três fatores importantes: os referenciais teóricos, a "observação ativa" do investigador e as características cinéticas de nosso objeto, se nos referimos às produçōes do homem, enquanto representantes de seu próprio funcionamento anímico.

Aqui já contamos com alguns pontos de partida para o mapeamento das reflexōes que serāo desenvolvidas neste trabalho. As experiências que habitam o universo do psicanalista, no que concerne aos variados movimentos de seu pensamento clínico e teórico, podem servir como referência útil de investigação para outras disciplinas?

\section{Navegar é preciso}

Há cerca de cem anos (1895) estabeleceu-se o início de uma inacabada obra, ao que tudo indica, interminável. Seja pela publicaçāo dos "Estudos sobre a Histeria" ou, principalmente, pelo surgimento de um interesse de Freud em pesquisar os conteúdos de seus próprios sonhos, estava germi- nando um novo campo de conhecimento destinado a movimentar radicalmente vários saberes pré-existentes; tanto aqueles tangentes à representação do homem, como também aqueles saberes que pretendiam representar a própria realidade que envolvia o sujeito.

Passado um século do nascimento da Psicanálise, há que se reconhecer que Freud ainda é atual. Podemos nos perguntar o porquê da afirmação, se seu desaparecimento (1939) já nos é distante e se sua obra semeou tantas contribuições posteriores, frutificadas em sólidas teorias psicanalíticas. Estas, transformaram-se em escolas, alargando assim, os horizontes do of́́cio psicanalítico, como é o caso de Klein, Lacan, Bion, Winnicott, Laplanche e tantos outros, que, ilustres ou não, marcam de maneira muitas vezes brilhante, em vários países, uma história de acréscimos sucessivos. Permanece a questāo: qual é o sentido deste apego matricial que ainda faz do "pai da Psicanálise" um parâmetro de atualidade? A resposta não é simples nem consensual, mas tende a apontar para um ponto de convergência: sua obra foi crivada por uma atitude de tolerante permeabilidade djalógica em relação a um objeto que pode, num instante, mostrar seus contornos e descortinar seus conteúdos, como pode também desaparecer no momento subseqüente, deixando no observador a sensação de que a nitidez anteriormente verificada poderia muito bem tratar-se de miragem. A permeabilidade constante, que parece ser apenas um traço de personalidade do célebre autor, é na verdade, um posicionamento nuclear do ofício psicanalítico (consubstanciado no método), sem o qual não se logra uma possibilidade analítica diante das manifestaçōes inconscientes. Sedimentação e deriva são disposiçōes mentais ativadas na exploração dos mares desconhecidos de cada sujeito, em cada situação, se quisermos nos servir de imagens e sentimentos expressos pelo proprio Freud: 
"3 de janeiro de 1.897

Querido Wilhelm.

Não havemos de naufragar. Em vez do canal que estamos procurando, é possível que encontremos oceanos cuja exploraçăo mais minuciosa há de ficar para aqueles que vierem depois de nós; mas, se nấo soçobrarmos prematuramente, se nossa constituiç̧̃o conseguir agüentar, chegaremos lá. Nous y arriverons. É só the darem mais dez anos e concluirei as neuroses e a nova psicologia....Nos momentos que passo sem angústia, ainda me sinto pronto para enfrentar todos os demônios..." (MASSON, 1986, p. 220)

Percebemos que estudar Freud (ou reestudar) não é apenas uma estratégia de bom senso pedagógico, que recomenda partirmos de um estágio elementar para um posterior avanço a estágios mais adiantados, de onde, mais sofisticados aprendizes, podemos abraçar uma Psicanálise mais evoluída, bem delineada e supostamente mais eficaz em seus propósitos terapêuticos. Ainda que pesem os efcitos enriquecedores a a esta altura imprescindíveis da vasta cultura psicanalítica posterior a Freud, seu legado está longe de ser considerado rudimentar; ele nos é profundo, enigmático e surpreendentemente provocativo a cada leitura. Enfim, é um trabalho que mantém sua vitalidade; uma originalidade (científica?) a apresentar-se como produto de constantes movimentos na abordagem do objeto, fomentados pela ação simultânea entre teoria e clínica. Monzani é extremamente feliz na ilustração dos movimentos do pensamento freudiano:

"Duas imagens ou metáforas nos parecem indicar, para se fixar o pensamento, esse movimento do pensamento freudiano: o pêndulo e a espiral. De um lado o discurso freudiano aparece como claramente pendular. isto $\hat{e}$. ora enfatiza um polo da questāo, ora seu oposto...Seguindo, porém esse movimento pendular. percebemos que ele acaba formando, quando penetramos nessa rede complicada que $\hat{\epsilon}$ o freudisıno, um movimento espiralado. com a condição de se pensar essa imagem no espaço e cilindrica. mente, onde as mesmas questōes são abordadas, "esquecidas", retomadas, mas não no mesmo nivel que estavam sendo tratadas anteriormente..." (MONZANI, 1989, p. 303)
A Psicanálise parece ser, curiosamente, uma resultante do conhecimento acumulado pelas Ciências Humanas e Biologicas, sem se parecer exatamente com nenhuma delas; o homem psicanalítico configura-se de maneira absolutamente singular, porém mantendo, pontualmente, associações possíveis com visōes de homem encontradas em diversas disciplinas. Nas palavras de Garcia-Roza, “onde situar a Psicanálise? A resposta pode ser: em nenhum lugar précxistente. A Psicanálise teria, nesse caso, operado uma ruptura com o saber existente e produzido seu próprio lugar. Epistemologicamente, ela não se encontra em continuidade com saber algum, apesar de arqueologicamente estar ligada a todo um conjunto de saberes sobre o homem, que se formou a partir do século XIX." (GARCIA-ROZA, 1984, p. 22 )

Quanto aos meios para a prospecção deste complexo objeto, o homem do inconsciente, podemos dizer que aí reside outra marcante singularidade, pois o método psicanalítico de investigação presta-se a acompanhar as características dinâmicas da realidade psíquica que ele mesmo, o método, ajudou a conceber. Sim, método concebendo e sendo concebido pelo fenômeno. Podemos nos perguntar: Teria faltado a Frcud uma clementar conduta científica que prescreve o isolamento de fatores de contaminaçāo para garantir a "pureza" dos fenômenos observados? Ou, ao contrário, Freud teria caminhado penosamentc rumo d̀ transcendência daquilo que os parâmetros positivistas limitaram à definição de ciência? Parece que assim tocamos num debate atual, que nảo se restringe aos meios psicanalíticos. É possível que algumas reflexõcs, somadas a recortes da história da Psicanálise, nos ajudem a pensar em prováveis implicaçōes da relação investigador-objeto; relação esta que demanda sempre um certo senso de cquilíbrio, diante da tarefa espinhosa e interminável de "atualização" permanente da noção de ciência.

Coloca-se aqui a necessidade de expedicionarmos produtivamente pelas diferentes áreas da pes- 
quisa humanista, exageradamente apartadas por fronteiras que a racionalidade defensiva estabeleceu nas instituições. Lembremos, contudo, que a preocupação que nos inspira diz respeito à postura do indivíduo pesquisador e nāo da formação institucional que ele vivencia (este seria um tema relevante para ser desenvolvido em outra situação). A questão central concerne à "tentação reducionista" pela qual passa o investigador, na captura de seu objeto, talvez pela justa necessidade de sentir a segurança proporcionada pelo continente de sensatez científica. Interessa-nos discutir se deste esforço não resultaria um afastamento em relação ao objeto real que, em função de sua constituição fragmentária, só pode ser representado mas jamais apreendido em essência. Uma formulação ao mesmo tempo simples e sofisticada nos oferece Fabio Herrmann, ao situar a Psicanálise diante de sua principal criação, o homem psicanalítico:

"Nossa prática tem alcançado sua meta clínica com sucesso bastante para assegurar-lhe posiçāo dominante na cultura con. temporânea. É hoje um dos caminhos mais importantes para que o homem saiba de si mesmo e é um saber que cura. De que cura a Psicanálise? Com toda sinplicidade podemos responder: a Psicanálise cura o homem de seu esquecimento. Na sociedade contemporânea observa-se um movimento ao mesmo tempo excêntrico e fragmentador. Os caminhos da tecnologia afastam o homem de seu centro e o rompem em pedaços, identificados com sempre mutáveis projetos de satisfaçåo, criados pelo próprio sistema de aceleração cultural que adia, a cada inomento, a condifão de satisfação c repouso que parece esıar buscando consıruir. A Psicanálise pretende curar do descentramento fragmentário, não por restituir ao homem o centro perdido, fantasia religiosa, mas por revelar seu descentramento essencial $\mathrm{e}$ a insaciabilidade do desejo." (HERRMANN, 199Ia, p. 14)

Corremos o risco de nos envolvermos com realidades virtuais quando tratamos de Humanidades, se nos limitamos a trabalhar no campo das expressōes manifestas do homem. $O$ advento do inconsciente freudiano nos conduziu à consideração de um universo latente que pulsa à sombra da consciência; pôs à mostra o habitat da realidade interna, atribuindo-lhe vida autônoma em relação às auto-representaçōes do indivíduo, forjadas conscientemente. Há que se preservar, contudo, a validade deste Eu consciente, produtor do discurso manifesto, instância onde se dá a representação unitária do sujeito; daí a noção de identidade, fator estruturante da vida psíquica, por onde se pode ter acesso ao inconsciente. $O$ que se quer salientar com essas ressalvas é que o real do homem se situa na interação entre complementares patamares da realidade. Nem aqui, nem ali, está nosso objeto; ele, o real, se apresenta no contraste entre realidades, o que significa que podemos supor virtuais quaisquer tentativas de se fazer da parte, o todo.

Neste final de século/milênio esboça-se de forma bastante contundente este tipo de debate nos meios psicanalíticos, como tentativas de se manter a Psicanálise semelhante aos movimentos humanos, ao invés de retê-la em teorias fechadas, representantes de práticas clínicas demasiadamente impessoais, apegadas a condutas padronizadas. Caminha-se pelo fio da navalha; sempre à espreita está uma espécie de desequilíbrio, em que a tirania da precisāo e da certeza pode inibir a troca de experiências singulares; aquelas que partem de um não-saber e que, digase de passagem, são justamente os elementos que animam o desenvolvimento psicanalítico, seja no campo tcórico ou na situaçāo cotidiana da prática clínica. Desta rica e intrincada discussão depende a própria vitalidade da Psicanálise: que o analista sustente a manutençāo de espaços abertos para os movimentos que têm lugar em si mesmo, no paciente, na teoria etc. Inferindo que o pesquisador em História, dentro de sua realidade específica, tiraria algum proveito do material que apresentamos, podemos reiterar o que é o fio condutor desta reflexão: somos feitos de movimentos. Se queremos saber de nós mesmos, navegar é preciso. 


\section{O todo e as partes: movimentos que inauguram a investigação dinâmica}

Os historiadores nāo teriam dificuldades para bem caracterizar o cenário histórico em que nasce a Psicanálise: Viena em franca e diversificada expansão populacional, na segunda metade do sćculo XIX, atraindo pessoas de todas as regiōes do Império austro-húngaro. Com clas, as conseqüências sociais do crescimento frenético, como o descmprego, a falta de moradia, a prostituição, o alcoolismo etc. $O$ Império Habsburgo conhecia um declínio gradual pela perda de territórios, pelos graves abalos financeiros decorrentes das campanhas e pelos constantes conflitos com as diversas nacionalidades que conglomerava. Contudo, Viena parecia flanar sobre a crise; uma outra face, de vida cultural intensa, de produção artística e científica diversificadas criavam uma realidade paralela, um forte contraste com a decadência econômica e social, cstas mantidas à margem da identidade cultural vienense, até as vésperas da virada do século.

Tudo parece indicar que a tensāo entre contrastes tenha servido como disparador de uma célula crítica na intelectualidade vienense que, por sua vez, envolta numa atmosfera sombria e intimista, alimentava um ceticismo profundo quanto à existência da unidade, scja ela o Estado, seja ela o indivíduo. Assim, a particularidade histórica em que a unidade imperial encontra-se em franco debàcle, fragmentada por divisōes nacionalistas, parece ser um importante ingrediente para as expressōes literárias e científicas da época, cujo pano de fundo é sempre o conflito entre a unidade e suas partes. Resumidamente, a Modernidade Vienense da virada do século estava marcada por um senso de que movimentos contraditórios facultavam à "unidade" um lugar de realidade virtual. A transitoriedade permanente, produto de pulsaçōes parciais, já não seria apenas uma característica de superfície do homem, mas provavelmente, sua mais essencial definiçāo.

Situado brevemente o contexto histórico $\mathrm{cm}$ quc se dá scu nascimento, voltemos a Psicanálise. Dentro de uma perspectiva clínica, Freud vai, desde cedo, a partir do tratamento de pacientes histéricas, postular a condição existencial de um ser dividido, adoecido pelo esforço de representar-se como unidade coerente em relação às moçōes inconscientes, animadas representativamente, por uma sexualidade incompativel (impulsos "absurdos", fantasias "degradantes") com a história de um Eu respeitável, contribuinte dedicado ao zelo pela família e por todas as formas de sedimentaçāo social. Sem negar o conflito entre as demandas do indivíduo e as exigências da vida $\mathrm{cm}$ sociedade, Freud vai transpondo, para o interior do próprio indivíduo, uma conflitiva de características constitutivas, onde se verifica um jogo pulsional $\mathrm{em}$ que convivem tendências "disruptivas" do aparelho psíquico, motivados exclusivamente pela obtenção de prazer e, numa especie de oposição complementar, as tendências "conjuntivas", destinadas a manter preservada a representação identitária do Eu, orgânica e socialmente (pulsōes sexuais e pulsōes do ego ou de auto-conservação, respectivamente, na primeira versão da (coria das pulsōes). Assim, passada quase uma década de tentativas metodológicas para que se chegasse a um tratamento que desse conta dos fenômenos psíquicos surgidos na clínica, somadas a outras tentativas teóricas para mapeá-los, Freud alcança, em 1.905, a base do que seria o início de sua teoria pulsional, com os Três Ensaios sobre Sexualidade.

A investigação psicanalítica teria que dar conta de corresponder a um conjunto de fatores dinâmicos, constituintes do aparelho psíquico e assim adentrar no trânsito de forças parciais contrastantes. A Psicanálise buscaria a edificação do método, $\mathrm{cm}$ conformidade com a realidade psíquica que $0 \mathrm{~cm}$ brião metodológico pôde encontrar e em sintonia com uma teoria psicanalítica que, embora inacabada, 
já era suficientemente consistente como campo de conhecimento autônomo em relação a sua nascente organicista. Talvez seja oportuno lembrar que estamos tangenciando a problemática da investigação de um objeto instável e que este mesmo objeto é aquele que faz a História e que, por sua vez, é feito por ela.

Em 1912, surge numa linguagem normativa, dentro de um conjunto de textos chamados de técnicos, um trabalho de Freud entitulado Recomendaf́ôes aos médicos que exercem a Psicanálise. O recorte de um pequeno trecho parece indicar ingenuamente o caminho a ser tomado pelo investigador para que conheça, do modo mais realista possível, os conteúdos do indócil objeto:

“... A técnica, contudo, é muito simples, Como se verá, ela rejeita o emprego de qualquer expediente especial (mesmo o de tomar notas). Consiste simplesmente em năo dirigir o reparo para algo específico e em manter a mesıma "atençăo uniformemente suspensa" (como a denominei) em face de tudo o que se escuta. Desıa maneira poupamos de esforço violento nossa atençāo... Pois assim que alguém deliberadamente concentra bastante a atençāo, começa a selecionar no material que the é apresentado; um ponto fixar-se-́́ cm sua mente com clareza particular e algum outro será, correspondentemente, ncgligenciado, e, ao fazer essa seleçảo, estará seguindo suas expectativas ou inclinaçỏes. Isto, contudo, é exatamente o que não deve ser feito. Ao efetuar a seleçăo, se seguir suas expectativas, estara arriscado a nunca descobric nada aléın do que já sabe; $c$, sc seguir as inclinações, certamente falsificará o que possa perceber. Nāo se deve esquecer que o que se escuta, na maioria, são coisas cujo signifícado só é identificado posteriorınente ... A regra para o médico pode ser assim expressa: ele deve conter todas as infuências conscientes de sua capacidade de prestar atenção e abandonar-se inteiramente à "memó ria inconsciente"..." (FREUD, 1987, p. 149 e 150 )

Freud reitera que o analista ao entregar-se ao que hoje chamamos dc "atenção flutuante", estaria, por assim dizer, procedendo à contrapartida do que é solicitado ao paciente, como "regra de ouro" da análise: que comunique tudo o que the ocorre sem crítica ou seleção. É evidente que tanto una recomen- dação como a outra (para o analisando e para o analista) serão transgredidas. Não há nenhuma ilusão quanto a isso, mas há a existência de um parâmetro que, introduzido pelo médico, possibilita a aferição do esforço com que o profissional e o cliente podem dedicar à manutenção das respectivas representações que fazem de si mesmos. Portanto, através de um conflito representacional, podemos observar, a título de ilustração, o que a norma técnica traz em seu núcleo: movimentos de ruptura e movimentos de conservação como aspectos estruturais do humano, que só podem ser contatados pelo investigador que se permite movimentar-se a si mesmo.

O psicanalista procura circular pela narrativa exposta pelo paciente, aberto a uma escuta que toma a história factual, nāo como realidade a ser conhecida para que cheguemos à verdade, desfeitas as distorções cometidas pelo sujcito. Ao contrário, o fato a ser investigado pelo analista é justamente aquele que engloba contrastes e lacunas; é na movimentação imprecisa que se encontra o sujeito. A realidade crível é aquela onde, naturalmente, cria-se uma história real, carregada de incongruências, no intento de contá-la pura, livre dos viezes do narrador. Nesse sentido, uma provável contribuição da Psicanálise, que vai além dos conceitos que foram incorporados pela produção intelectual do século $\mathrm{XX}$, resulta em sugerir que o investigador coloque sua subjetivjdade em situação de deriva investigativa diante da obra humana, num claro e divergente apêndice à metodologia científica clássica. Assim, Freud que nos chamou a atenção para o fenômeno da transferência e de sua contrapartida, a contra-transferĉncia, como elementos inerentes de um processo analítico, parece ter tocado num ponto nodal da prática clínica, ao propor que tais fatores possam encontrar uma reconhecida existência, ao invés de serem proscritos. Esta scria uma postura fundamental para que as diversas incidências cmocionais encontradas na dupla analítica, não provocassem efeitos deletérios para o próprio tratamento. Em outras 
palavras, temos uma perspectiva clínica refinada, que propõe o conhecimento dos conteúdos no lugar da evitação; é bom que conteúdos sejam conhecidos para que nāo sejam atuados. Aprendemos, como analistas, a usar como instrumento as várias experiências internas que uma relação analítica pode nos suscitar. Isto representa um dos muitos desafios do ofício psicanalítico, pois define grande parte das exigências que a Psicanálise faz a quem se dedica a ela em sua dialética teórico-clínica: uma prática de investigaçāo que coloca o analista em movimentos mentais situados entre a sedimentação e a deriva.

Parece bastante plausível inferirmos a ocorrência de uma trajetoria mental semelhante em "investigadores de homens" oriundos de outras disciplinas vinculadas à pesquisa humanista. Contudo, para que possam servir-se das experiências metodológicas e das bases conceituais psicanalíticas sem maiores reservas, há um ponto resistencial a ser corretamente equacionado: alega-se que Freud teria se dedicado à análise do indivíduo e que construiu sua obra a partir dessa referência nuclear. Sendo assim, a Psicanálise não se presta à análise do sujeito colctivo, objeto do historiador, do sociólogo e de outros profissionais. Talvez tenham razão aqueles que defendem esta perspectiva. Mas por outro lado, como fazer uma análise do coletivo que seja minimamente convincente, no final do século XX, negando à Psicanálise uma participação conceitual, mesmo que indireta, através daqueles conceitos fundamentais que nos revelaram um homem que dá vida à sopa de neurônios como queriam os médicos e que anima a luta de classes, dentro do referencial materialistahistórico? Tentemos, portanto, uma formulação menos paralisante.

A Psicanálise realmente não desenvolveu uma psicologia do coletivo; a rigor, ela não existe em lugar algum. O que temos são trabalhos sérios, como o de Jung, por exemplo, que seguem uma trajetória apoiada na comprovação, no reconhecimento, de um inconsciente coletivo, aspecto constitutivo da psique de um sujeito coletivo. É possível que passemos muito tempo ainda nos deliciando com esta "descoberta". Contudo, para o exercício pleno de reconhecimento deste objeto, para atingirmos a maturidade interpretativa de seus conteúdos, precisamos saber como funciona esta psique, formadora de mitos, lendas e outras manifestações da ordem do simbólico; esse processo implica necessariamente no esforço multidisciplinar, destinado à "construção homeopática" de um conhecimento que não possui um só senhor. Se um dia existir, será um conhecimento criado por pesquisadores de diversas áreas, bem dispostos a abrir seus métodos clássicos de investigação, esperando que de seu trabalho emerjam os esclarecimentos $\mathrm{e}$, sobretudo, os renovados pontos lacunares. Será, provavelmente, obra sustentada por movimentos exploratórios da mente investigadora, no trânsito entre a sedimentação e a deriva; movimentos despojados da demanda de objetivação sedimentada que, se totalitária, só abre acesso à realidade virtual.

\section{Transcendendo o saber: procura-se o não-saber}

Já há alguns séculos, o termo realidade sc confunde com verdade e palavras como fantasia ou imaginação são identificados com mentira. Contudo, há cerca de um século, a Psicanálise parecia colocar uma cunha neste sistema tirânico da objetividade, de maneira a provocar-Ihe uma profunda $e$ promissora fenda. Quando os pacientes histéricos eram tratados com preconceito (no saber oficial eram farsantes, pois como ditavam os veredictos médicos, "eles não tinham nada"); quando os sonhos eram produtos de algum embaralhamento de origem neurológica; e, quando o desejo era simplesmente um núcleo perturbador da organização social (um tipo de fraqueza do homem inferior), surge a "libertação"! Concebido com um inconfundível traço de simplicidade científica, nasce um autêntico nāo-sa- 
ber, que, por ser um não-saber, vai promovendo uma notável desconstrução em supostos saberes que se pretendiam estáveis e absolutos. Através da investigaçāo apaixonada, revelou-se a Freud a mentira travestida de verdade.

A Psicanálise nos ensina penosamente, diga-se de passagem, a sustentar um não-saber que garante a sobrevivência do objeto homem. Tentamos nāo saber, isto é, saber apenas pontualmente, para preservar os movimentos que caracterizam o real. Realidade é um termo que se presta a carregar as marcas do tempo; desde que se admite um interior no homem (fenômeno nada novo que foi proscrito durante alguns séculos pela ciência) e, principalmente, desde que se conhece um pouco sobre seu funcionamento, sabemos que, quando nos referimos àquela realidade dos positivistas, concebida num dado período histórico, estamos criando uma virtualidade. Virtual é a tentativa rebelde da parte, em proclamarse como única realidade.

U̇m bom exemplo oferecido por Freud, quanto ao conflito entre realidades (o real e o virtual), está registrado numa carta ao amigo Fliess, escrita em 21 de setembro de 1.897. Trata-se de uma transformaçāo na teoria das neuroses, que abriu muitos caminhos para o desenvolvimento posterior da Psicanálise:

"Querido Wilhelm,

...E agora quero confiar-Ihe de imediato, o grande segredo que foi despontando lentamente $\mathrm{em}$ mim nestes últimos meses. Não acredito mais eın minha neurótica (teoria das neuroses), Provavelmente, isso nảo será intełigível sem uma explicaçāo; afinal, você mesmo considcrou digno de crédito aquilo que pude the contar..." (MASSON, 1986, p. 265)

O grande segredo ao qual aludia Freud era, na verdade, o abandono da "teoria da sedução", pela qual pacientes neuróticas, segundo seus próprios relatos, teriam sido seduzidas na infância por algum adulto, mais precisamente por scus pais. Durante vários anos cste discurso foi considerado in totum verdadeiro; um fato histórico lamentável e surpreendentemente comum na vida das histéricas que, pela inverossímil incidência, levou o analista a desconfiar. A partir da improbabilidade de uma perversāo adulta em massa, que se manifestava por ataques sexuais contra seus proprios filhos; considerando o teor sensual que as pacientes depositavam na relação com o médico; e, finalmente, em função dos próprios fracassos clínicos, Freud foi formulando a hipótese, posteriormente confirmada e desenvolvida, de que havia ali um fato sim, porém um fato que representava a história de uma realidade submersa: uma realidade altamente dinâmica, cujo desvendamento acelerou a evolução de conceitos fundamentais para a Psicanálise, como é o caso da fantasia, da sexualidade infantil e do complexo de Édipo, sem contar os desenvolvimentos paralelos verificados, na compreensão da transferência e na construção de toda uma teoria sexual que, em Freud, rão cessou seus movimentos até a chegada dos anos 30.

Do fato histórico ao fato psíquico, a Psicanálise evoluía na pesquisa dos núcleos patogênicos das neuroses e assim sedimentava seu desenvolvimento metodológico. Todavia, o tempo foi revelando a virtualidade, tanto de uma hipótese como de outra; o real é, simultaneamente, o histórico e o psíquico em um conjunto indissociável de implicações mútuas. Sobre a "teoria da sedução", destacamos a atividade fantasiosa da criança (o psíquico), no exercício de sua sexualidade, mas acrescentamos que esta sexualidade infantil ê forjada na açāo da subjetividade parental, ao imprimir na criança os traços de uma sexualidade adulta que nela permanecerá como um "enigma estrangeiro" (o histórico). Claro está que não estamos tratando da cena factual onde o adulto ataca sexualmente uma criança; a modalidade de invasão a que nos referimos é silenciosa, natural e incorporada às experiências mais básicas da humanidade, como revela Laplanche: 
"Um signo proposto pelo adulto da criança, forjado por ele na situaçăo, antes que a propria criança acabe esse recolhimento. Ora, é bem por af, e unicamente por af, que podeınos conceber a intervenção do sexual na experiência de satisfação. Aqui eu vou evidentemente bem alên de Freud. É o adulto que coloca $\mathrm{em}$ primeiro plano o seio - e nd̆o o leite - e isso em funçżo de seu proprio desejo consciente e sobretudo inconsciente. Pois o seio nũo é somente um órgão destinado a alimentar a criança, mas um órgåo sexual, o que é perfeita e completamente escotomisado por Freud $e$ depois de freud. Nenhum texto, nenhuma alusão, mesmo de Freud. leva em conta a excitabilidade do seio feminino, năo somente no aleitamento mas simplesmente na vida sexual da mulher". (LAPLANCHE, 1993, p. 15)

A Psicanálise está, via de regra, em contraste com a Historia e assim deve permanecer, cumprindo seu papel histórico. Contraste aqui tem um sentido preciso: não aquele que faz oposição maniqueista à objetividade material, como se fosse um dos pólos do "cabo de guerra" (esse tem sido um equívoco recorrente na abordagem do assunto); o papel histórico contrastante reside em lembrar o homem da instabilidade dos fatos que pretende sedimentar e em indicar-lhe metodologicamente, o caminho pelo qual se pode transitar, com algum sucesso, pela dinâmica que é estrutural no humano, como decorrência de sua "anatomia" fragmentada.

O psicanalista, ao contrário da caricatura, é aquele que quase nada explica. Quando o faz, normalmente é a contragosto. Explicar é a ação em sentido oposto ao da análise. A análise é dada à dinâmica e permeável a curtos momentos de síntese. Por isso, para nos entregarmos aos tantos movimentos da natureza humana, é que precisamos da história como parâmetro pelo qual se tem o contraste. Sem a história, o analista não conhece nada além do que já sabe, não tem acesso à singularidade de seu paciente. Esse quadro é originalmente descrito por Fabio Hernnann:
"O analista suspeitoso não se contenta com o inierpretóvel, quer ver o fundo do homem, descasca camada por camada de seu cliente até que, no fundo, que vai encontrar? Quatro, seu retrato! Pois no fundo da alma humana esconde-se um ceno espelho em que se unira o analisı das profundezas, aquele que suspeita de toda a aparência, abismado ao ls descobrir o reflexo da propria identidade ou o de sua teoria predileta. No fundo todos ós homens sto iguais, por isso é que o fundo nåo interessa; interessanos a espessura da superfície representacional, onde reside a peculiaridade de cada vida psiquica." (HERRMANN, 199l, p. 146)

Por outro lado, pode-se supor, sem a consideração da dinâmica psíquica, o historiador também perde a singularidade de seu objeto, represenitandoo apenas a partir de conteúdos manifestos que acabam por confirmar teses gerais de comportamento coletivo, diante de uma dada conjuntura social, econômica ou políticá.

A rigor, a Psicanálise como disciplinả não é con- diçāo para um historiador trabalhar em História; nem a História como campo de conhecimento é condị̧̧ão para o psicanalista fazer o seu trabalho. $O$ argumento que expressamos 6 de outra natureza: na especificidade de seus afazeres, há um historiador no analista e há um analista no historiador, desde que estes se permitam transitar por diferentes disposiçōes mentais, aceitando o desafio de se navegar por águas, a princípio, desconhecidas.

A singularidade do objeto requer, a consideração dos movimentos que envolvem, simultaneamente, 0 psíquico e o histórico. Reconhecer possibilidades "estrangeiras" na abordagem do fenômeno ou sim. plesmente reconhecer sua existência, pode significar a máxima aproximação possível do real deste homem. Façamos o luto pela perda de nossos objetos virtuais, previsíveis e estáticós.

Nous y arriverons. 


\section{Bibliografia}

AUDEN, W. H. Ponemas. Săo Paulo, Companhia Das Letras, 1986. FREUD, Sigmund. "Três Ensaios Sobre a Teoria da Sexualidade" in Obras Completas de Sigmund Freud. Rio de Janeiro, Imago, 1987.

. Sigmund. "Recomendações Aos Médicos Que Exercem A Psicanálise" in Obras Completas de Sigmund Freud. Rio de Janeiro, lmago, 1987.

GARCIA-ROZA, Luiz Alfredo. Freud e o Inconsciente. Rio de Janeiro, Zahar, 1984.

HERRMANN, Fabio. Andaimes do Real -livro primeiro- $O$ Método da Psicanálise. São Paulo, Brasiliense, 1991.

Clínica Psicanalirica-A Arte da Interpretação. São

Paulo, Brasiliense, $1991 \mathrm{~b}$.
LAPLANCHE, Jean. A revolufãos copernicana acabada. trad. M. L. Caleiro Costa e M.S. Deweik. Såo Paulo, Departamento de Psicanálise do instituto Sedes Sapientiae, 1993.

. Teoria da Seduçāo Generalizada. Porto Alegre, Artes Médicas, 1988.

MASSON, Jeffrey Moussaieff. A Correspondência Complesa de Sigmund Freud para Wilhelm Fliess/1887-1904. Rio de Janeiro, lmago, 1986.

MONZANI, Luiz Roberto. Freud-O Movimento de um Pensamen. to. Campinas, Editora da Unicamp, 1989.

SCHNITZLER, Arthur. Contos de Amor e Morte. São Paulo, Companhia das Letras, 1987. 